Chemotherapy 1991;37(Suppl. 2):I-III

\title{
Contents, Vol. 37, Supplement 2, 1991
}

Considerations in Comparing Intravenous and Intramuscular Antibiotics

Milkovich, G.; Piazza, C.J 1

Parenteral Antibiotic Therapy in Outpatients: Quality Assurance and Other Issues in a Protohospital

Eron, L.J 14

Imipenem/Cilastatin: Evolution of the Sustained-Release Intramuscular Formulation

Kahan, F.M.; Rogers, J.D 21

Twice Daily Intramuscular Imipenem-Cilastatin in the Treatment of Skin and Soft

Tissue Infections

Sexton, D.J.; Wlodaver, C.G.; Tobey, L.E.; Yangco, B.G.; Graziani, A.L.; MacGregor, R.R 26

Intramuscular Imipenem/Cilastatin Treatment of Upper Reproductive Tract Infection in Women: Efficacy and Use Characteristics

McGregor, J.A.; Christensen, F.B.; French, J.I

Intramuscular Imipenem as Adjuvant Therapy for Acute Cholecystitis and Perforated or Gangrenous Appendicitis

Yellin, A.E.;Heseltine, P.N.R.; Berne, T.V.; Appleman, M.D.; Gill, M.A.; Chenella, F.C 37 Intramuscular Imipenem/Cilastatin in Multiple-Dose Treatment Regimens:

Review of the Worldwide Clinical Experience

Garau, J.; Calandra, G.B 44

Overall Clinical Utility of the Intramuscular Preparation of Imipenem/Cilastatin MacGregor, R.R 